\title{
Gastrocolocutaneous Fistula: An Unusual Case of Gastrostomy Tube Malfunction with Diarrhea
}

\author{
Junghwan Lee ${ }^{1}$, Jinyoung Kim${ }^{1}$, Ha il Kim¹, Chung Ryul Oh${ }^{1}$, Sungim Choi', Soomin Noh ${ }^{1}$, Hee Kyong Na ${ }^{2}$ and Hwoon-Yong Jung ${ }^{2}$ \\ ${ }^{1}$ Department of Internal Medicine, ${ }^{2}$ Division of Gastroenterology, Department of Internal Medicine, University of Ulsan College of Medicine, \\ Asan Medical Center, Seoul, Korea
}

\begin{abstract}
A gastrocolocutaneous fistula is a rare complication of percutaneous endoscopic gastrostomy (PEG). We report a case of a gastrocolocutaneous fistula presenting with intractable diarrhea and gastrostomy tube malfunction. A 62-year-old woman with a history of multiple system atrophy was referred to us because of PEG tube malfunction. Twenty days prior to presentation, the patient started developing sudden diarrhea within minutes after starting PEG feeding. Fluoroscopy revealed that the balloon of the PEG tube was located in the lumen of the transverse colon with the contrast material filling the colon. Subsequently, the PEG tube was removed and the opening of the gastric site was endoscopically closed using hemoclips. Clinicians should be aware of gastrocolocutaneous fistula as one of the complications of PEG insertion. Sudden onset of diarrhea, immediately after PEG feedings, might suggest this complication, which can be effectively treated with endoscopic closure. Clin Endosc 2018;51:196-200
\end{abstract}

Key Words: Gastrostomy; Complications; Fistula

\section{INTRODUCTION}

Percutaneous endoscopic gastrostomy (PEG) is a safe and effective method for providing long-term enteral nutrition. However, previous studies have reported possible complications such as wound infection, tube dislodgement, peristomal leakage, bleeding, internal organ injury, necrotizing fasciitis, and aspiration pneumonia. ${ }^{1}$ Most complications are minor, but some rare severe complications may be life threatening. ${ }^{2}$ Gastrocolocutaneous fistula is a rare complication of PEG tube placement, with an incidence rate of $0.5 \%-3 \%{ }^{3}$ This complication develops from the perforation of the interposed

Received: April 25, 2017 Revised: July 20, 2017

Accepted: July 21, 2017

Correspondence: Hee Kyong Na

Division of Gastroenterology, Department of Internal Medicine, University of Ulsan College of Medicine, Asan Medical Center, 88 Olympic-ro, 43-gil, Songpa-gu, Seoul 05505, Korea

Tel: +82-2-3010-5676, Fax: +82-2-2045-4043, E-mail: hkna77@naver.com ORCID: https://orcid.org/0000-0001-6764-9099

(c) This is an Open Access article distributed under the terms of the Creative Commons Attribution Non-Commercial License (http://creativecommons.org/ licenses/by-nc/3.0) which permits unrestricted non-commercial use, distribution, and reproduction in any medium, provided the original work is properly cited. colon when a PEG tube is placed into the stomach. Affected patients usually remain asymptomatic for a few days to several months. Therefore, gastrocolocutaneous fistula is usually unrecognized until the tube is replaced or until typical symptoms develop. ${ }^{4}$ We report a case of a gastrocolocutaneous fistula that presented with diarrhea and gastrostomy tube malfunction.

\section{CASE REPORT}

A 62-year-old woman with a medical history of multiple system atrophy was admitted to our institution owing to gastrostomy tube malfunction that seemed to manifest during the day time. The patient had undergone uneventful PEG four months ago and had been fed without difficulty via the PEG tube. However, twenty days prior to presentation, the patient had begun to develop sudden diarrhea within minutes after starting PEG feedings. She had been treated with antidiarrheal medication, but it had proven ineffective. Subsequently, the PEG tube was clogged, and the patient was referred to the emergency department. 

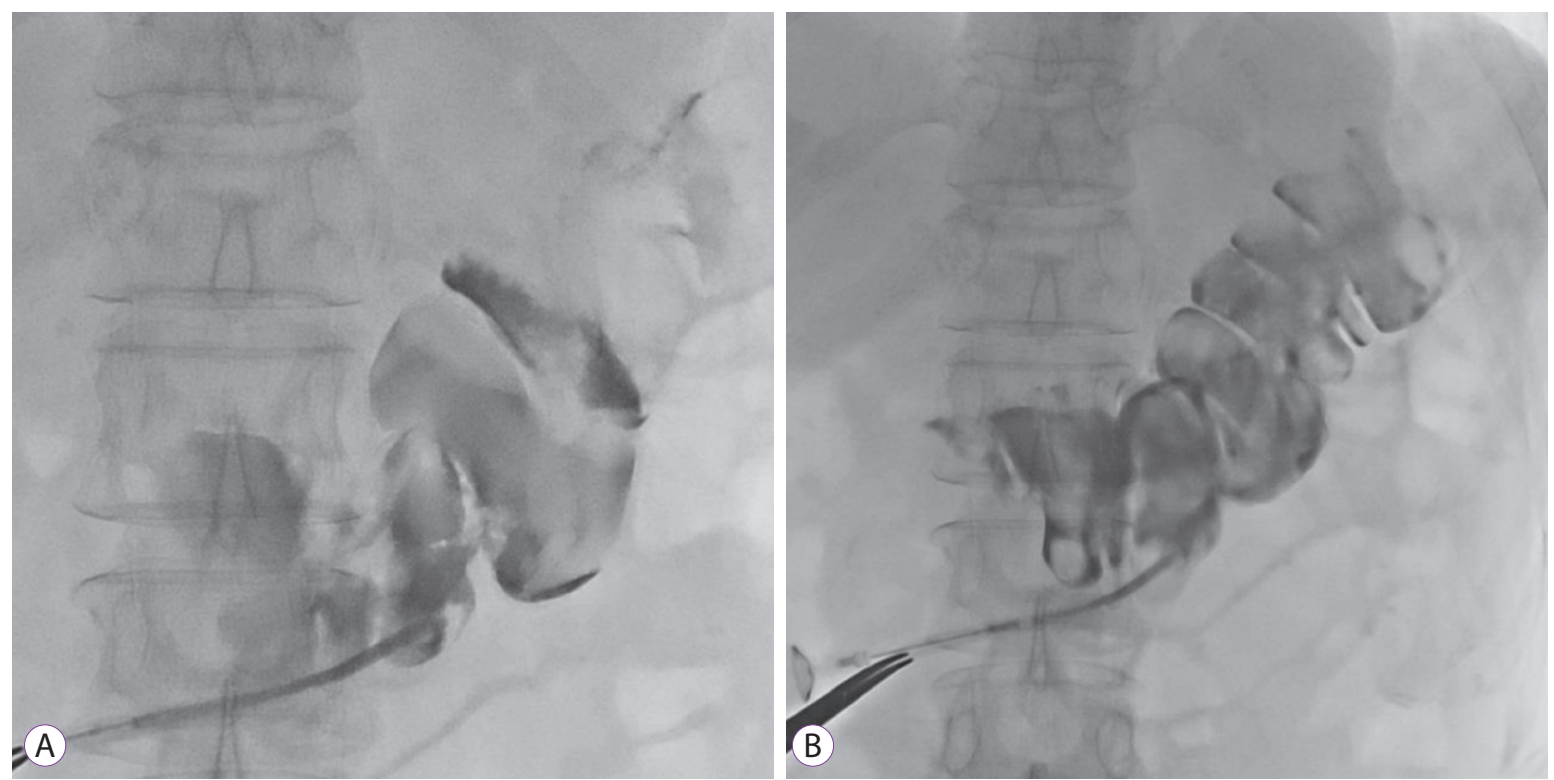

Fig. 1. (A, B) Contrast radiography with gastrografin showing the balloon of the percutaneous endoscopic gastrostomy tube in the lumen of the transverse colon with contrast filling in the transverse colon.
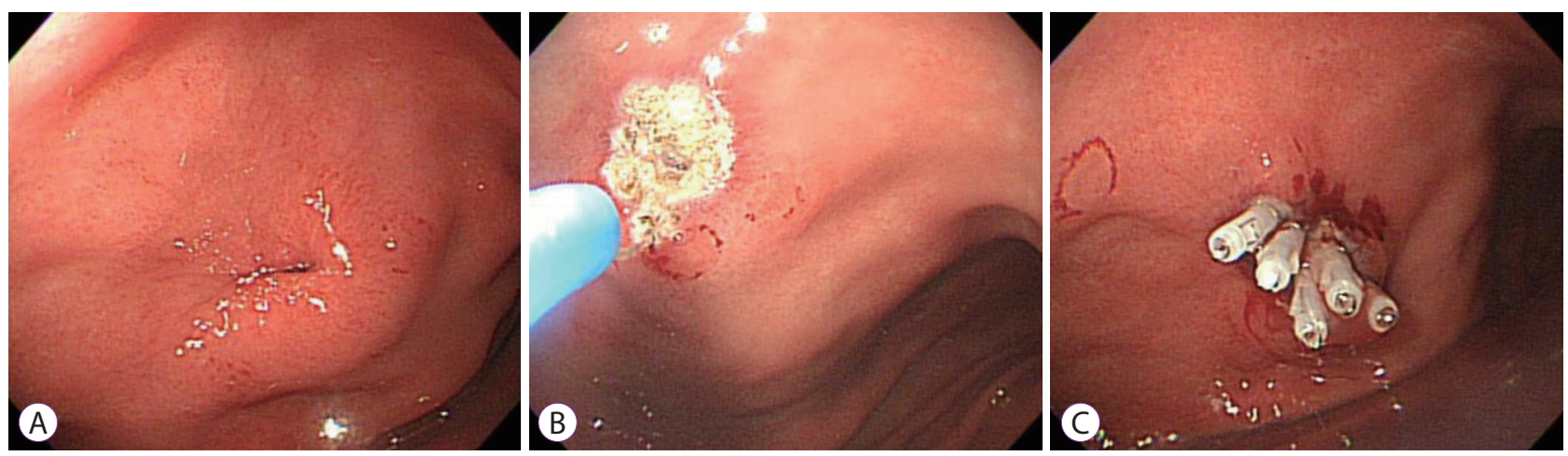

Fig. 2. Endoscopic findings. (A) The gastric side of the fistula opening is shown at the anterior side of the body (B) Argon plasma coagulation was applied to the fistula opening. (C) Hemoclips were applied to close the fistula opening.

The patient was hemodynamically stable, and physical examination revealed a soft and flat abdomen with normal bowel sounds. Laboratory findings were all within normal limits. A radiologic study with gastrografin, administered through the PEG tube, showed the balloon of the PEG tube in the lumen of the transverse colon with the contrast material filling the transverse colon (Fig. 1). The PEG tube was immediately removed, and the gastric side opening was endoscopically closed using argon plasma coagulation and hemoclips (Fig. 2).

Computed tomography (CT) of the abdomen and pelvis showed a linear tract anterior to the transverse colon, with the stomach located behind the transverse colon (Fig. 3). No pneumoperitoneum, abnormal fluid collections, or peritonitis was observed. One week after removal of the PEG tube, esophagogastroduodenoscopy (EGD) was performed. Fluoroscopy revealed that no contrast material had entered the colon or the peritoneal space when the contrast was shot through the EGD biopsy channel towards the previous gastrostomy site (Fig. 4). Follow-up CT scan showed obliteration of the previous fistulous tract, and enteral feeding was initiated via a nasojejunal feeding tube. Because the patient and her family refused to undergo additional PEG procedure, surgical gastrostomy was scheduled and the patient was sent back to a rehabilitation hospital.

\section{DISCUSSION}

Gastrocolocutaneous fistula is a rare complication of PEG, which occurs when a PEG tube penetrates the interposed colon between the abdominal wall and the stomach during the initial insertion of PEG. ${ }^{5}$ Adhesion from the previous lap- 


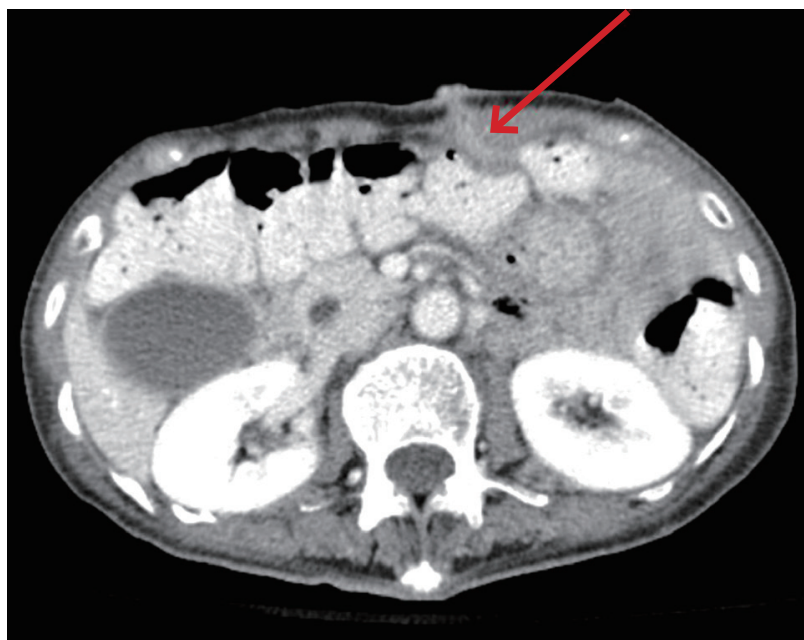

Fig. 3. Contrast-enhanced abdominal computed tomography revealing the gastrostomy tract in the left anterior abdominal wall anterior to the transverse colon.

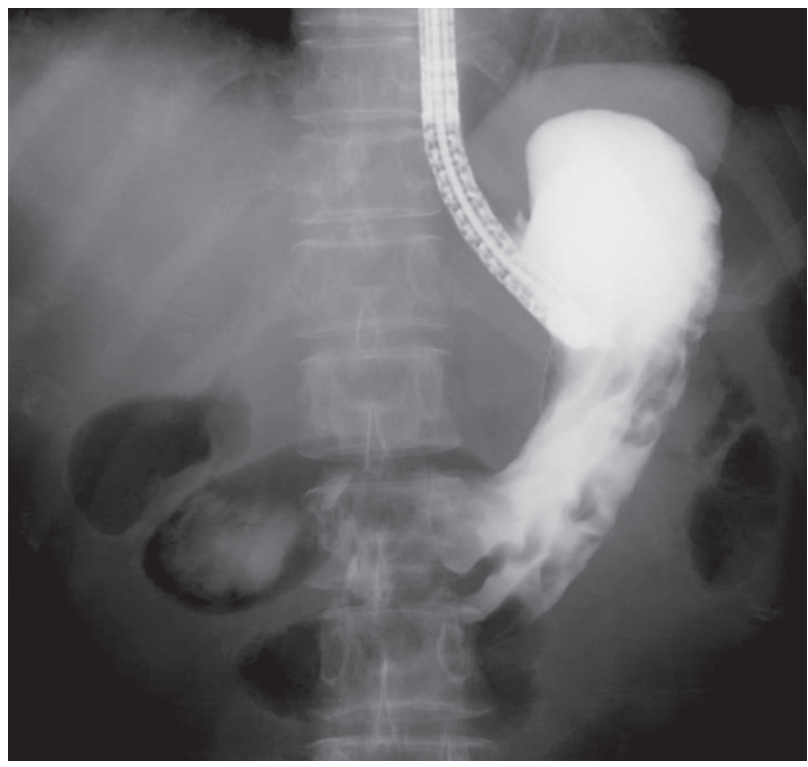

Fig. 4. One week after removal of percutaneous endoscopic gastrostomy tube, contrast radiography showing no evidence of gastric leakage.

arotomy has been suggested as one of the major risk factors for gastrocolocutaneous fistula; however, a previous review reported that only 8 of the 28 patients with gastrocolocutaneous fistula had undergone previous abdominal surgery. ${ }^{6.7} \mathrm{Sim}$ ilarly, our patient did not have a history of abdominal surgery. Gastroenterologists should consider the possibility of colonic interposition between the abdominal wall and the stomach during insertion of PEG tube, even in patients without a history of abdominal surgery. High-riding transverse colon, abnormal posture and spinal deformity, and over-distended stomach during EGD may contribute to the development of gastrocolocutaneous fistula. ${ }^{7-9}$

Although a gastrocolocutaneous fistula may form at the time of insertion of the PEG tube, symptoms may not manifest until the PEG tube migrates into the transverse colon or until the tube is replaced..$^{10}$ For patients who do not undergo tube replacement, an asymptomatic period may persist up to several months after the initial PEG tube placement. ${ }^{7}$ When the tube lodges in the transverse colon, patients present typical symptoms, such as sudden onset of diarrhea, within minutes after starting PEG tube feeding, and passage of undigested feeding formula. ${ }^{11}$ Appearance of fecal material in the PEG tube or feculent vomiting may also be a result of the retrograde passage of fecal material from the colon via the fistula. ${ }^{12}$ In our case, the typical symptoms manifested approximately 3 months after PEG procedure, and gastrocolocutaneous fistula was diagnosed when the patient was referred to our center owing to gastrostomy tube malfunction.

Several techniques have been suggested to minimize the risk of colon penetration. Strodel et al. suggested identifying the interposing colon between the abdominal wall and the stomach by aspirating a saline-filled syringe to detect air bubbles that appear before the endoscopic visualization of the needle in the gastric lumen. ${ }^{13}$ Excessive inflation of air into the stomach during PEG procedure makes the transverse colon interpose between the abdominal wall and the stomach; therefore, excessive inflation of air into the stomach should be avoided during the procedure. ${ }^{6}$ The use of ultrasound or CT scan can be considered in patients with complex abdominal anatomy. Techniques such as trans-illumination and finger pressure help guide the placement of the puncture site.

When gastrocolocutaneous fistula formation is suspected, upper endoscopy is recommended. Radiologic study with a water-soluble contrast medium or abdominal CT scan may help confirm the diagnosis. ${ }^{11}$ Colonic haustra and gastrostomy tract can be visualized through fluoroscopic images and CT scan, as in our case.

Data in the previous reports are insufficient to propose standard management for gastrocolocutaneous fistula. In most cases, treatment for gastrocolocutaneous fistula aims to allow spontaneous closure of the fistula by removing the feeding tube. ${ }^{4,7,9,14} \mathrm{~A}$ laparotomy is recommended only if there is an evidence of peritonitis. ${ }^{7,15,16}$ Previously reported cases in which gastrocolocutaneous fistula was conservatively treated are summarized in Table 1. ${ }^{4,7,914}$

There have been attempts at endoscopic treatment of fistulae after removal of PEG tube (Table 2). ${ }^{479,15-20}$ Hwang et al. suggested that endoscopic treatments would be helpful in cases where the fistula does not spontaneously close within several days. ${ }^{17}$ Kim et al. suggested that endoscopic closure would accelerate the blockage of the fistula in patients with a risk of delayed wound healing and infection (e.g., diabetes mellitus). ${ }^{18}$ We assume that endoscopic closure of gastrocolocutaneous 
Table 1. Conservatively Treated Cases of Gastrocolocutaneous Fistula after PEG

\begin{tabular}{|c|c|c|c|c|c|}
\hline Study & Age/Sex & Presentation & Underlying disease & $\begin{array}{l}\text { Onset of symptoms from } \\
\text { PEG insertion }\end{array}$ & Treatment \\
\hline Kim et al. $(2014)^{4}$ & $77 / \mathrm{M}$ & Loosening of PEG tube & Dementia & $33 \mathrm{mo}$ & $\begin{array}{l}\text { Removal of PEG } \\
\text { tube }\end{array}$ \\
\hline \multirow{5}{*}{$\begin{array}{l}\text { Friedmann et al. } \\
(2007)^{7}\end{array}$} & $84 / F$ & Fecal materials in PEG tube & Dementia & 5 wk after tube exchange & \\
\hline & $68 / \mathrm{M}$ & Fecal materials in PEG tube & Hemorrhagic stroke & $2 \mathrm{wk}$ & \\
\hline & $73 / \mathrm{M}$ & Diarrhea & Dementia & $14 \mathrm{mo}$ & \\
\hline & $75 / \mathrm{M}$ & Fecal materials in PEG tube & After surgery & $2 \mathrm{wk}$ & \\
\hline & $83 / \mathrm{M}$ & Fecal materials in PEG tube & Parkinson's disease & $\begin{array}{l}1 \mathrm{yr} \text { after } 2 \text { nd tube } \\
\text { exchange }\end{array}$ & \\
\hline Lee et al. $(2014)^{9}$ & $65 / \mathrm{M}$ & Fecal materials in PEG tube & Cerebellar infarction & 6 mo after tube exchange & \\
\hline Liu et al. $(2010)^{14}$ & $87 / \mathrm{M}$ & Diarrhea & Dementia & $1 \mathrm{mo}$ & \\
\hline
\end{tabular}

PEG, percutaneous endoscopic gastrostomy.

Table 2. Endoscopic or Surgical Treatment for Patients with Gastrocolocutaneous Fistula after PEG

\begin{tabular}{|c|c|c|c|c|c|c|}
\hline Study & Age/Sex & Presentation & $\begin{array}{l}\text { Underlying } \\
\text { disease }\end{array}$ & $\begin{array}{l}\text { Onset of } \\
\text { symptoms from } \\
\text { PEG insertion }\end{array}$ & $\begin{array}{l}\text { Treatment } \\
\text { (Endoscopic } \\
\text { or surgical) }\end{array}$ & $\begin{array}{l}\text { Detailed method of } \\
\text { treatment }\end{array}$ \\
\hline $\begin{array}{l}\text { Kim et al. } \\
(2014)^{4}\end{array}$ & $74 / \mathrm{M}$ & Diarrhea & $\begin{array}{l}\text { Cerebral } \\
\text { infarction }\end{array}$ & $9 \mathrm{mo}$ & $\begin{array}{r}\text { Endoscopic } \\
\text { treatment }\end{array}$ & $\begin{array}{l}\text { Removal of PEG tube and clipping at } \\
\text { the colonic side of the fistula }\end{array}$ \\
\hline $\begin{array}{l}\text { Lee et al. } \\
(2014)^{9}\end{array}$ & $47 / \mathrm{M}$ & $\begin{array}{l}\text { Fecal materials in } \\
\text { PEG tube }\end{array}$ & $\begin{array}{l}\text { Traumatic } \\
\text { subdural } \\
\text { hematoma }\end{array}$ & $12 \mathrm{mo}$ & $\begin{array}{r}\text { Endoscopic } \\
\text { treatment }\end{array}$ & $\begin{array}{l}\text { Removal of PEG tube and clipping at } \\
\text { the colonic side of the fistula }\end{array}$ \\
\hline $\begin{array}{l}\text { Hwang et al. } \\
(2012)^{17}\end{array}$ & $72 / \mathrm{F}$ & $\begin{array}{l}\text { Fecal materials in } \\
\text { PEG tube }\end{array}$ & $\begin{array}{l}\text { Medullary } \\
\text { infarction }\end{array}$ & 3 days & $\begin{array}{r}\text { Endoscopic } \\
\text { treatment }\end{array}$ & $\begin{array}{l}\text { Removal of PEG tube and clipping } \\
\text { at the colonic side of the fistula, } \\
\text { followed by gastric side clipping } \\
\text { and application of detachable snare }\end{array}$ \\
\hline $\begin{array}{l}\text { Kim et al. } \\
(2002)^{18}\end{array}$ & $53 / \mathrm{M}$ & $\begin{array}{l}\text { Diarrhea and } \\
\text { feculent vomiting }\end{array}$ & $\begin{array}{l}\text { Hypoxic brain } \\
\text { damage, diabetes } \\
\text { mellitus }\end{array}$ & $2 \mathrm{wk}$ & $\begin{array}{r}\text { Endoscopic } \\
\text { treatment }\end{array}$ & $\begin{array}{l}\text { Removal of PEG tube and clipping at } \\
\text { the colonic side of the fistula }\end{array}$ \\
\hline $\begin{array}{l}\text { Melmed et al. } \\
(2009)^{19}\end{array}$ & $82 / \mathrm{M}$ & Feculent vomiting & Not available & $12 \mathrm{mo}$ & $\begin{array}{r}\text { Endoscopic } \\
\text { treatment }\end{array}$ & $\begin{array}{l}\text { Removal of PEG tube and clipping at } \\
\text { the gastric side of the fistula failed. } \\
\text { Cardiac septal defect closure device } \\
\text { was applied. }\end{array}$ \\
\hline $\begin{array}{l}\text { Bertolini et } \\
\text { al. }(2014)^{20}\end{array}$ & $85 / \mathrm{M}$ & Diarrhea & Larynx cancer & $10 \mathrm{mo}$ & $\begin{array}{r}\text { Endoscopic } \\
\text { treatment }\end{array}$ & $\begin{array}{l}\text { Removal of PEG tube and closure } \\
\text { of the colonic orifice of the fistula } \\
\text { with over-the-scope-clip }\end{array}$ \\
\hline $\begin{array}{l}\text { Friedmann et } \\
\text { al. }(2007)^{7}\end{array}$ & $67 / \mathrm{M}$ & $\begin{array}{l}\text { Severe hunger and } \\
\text { diarrhea }\end{array}$ & $\begin{array}{l}\text { Schizophrenia, } \\
\text { recurrent bowel } \\
\text { obstruction }\end{array}$ & $1 \mathrm{mo}$ & $\begin{array}{l}\text { Surgical } \\
\text { treatment }\end{array}$ & Elective surgical gastrostomy \\
\hline $\begin{array}{l}\text { Huang et al. } \\
(2005)^{15}\end{array}$ & $44 / \mathrm{M}$ & Diarrhea & Tonsil cancer & $2.5 \mathrm{mo}$ & $\begin{array}{l}\text { Surgical } \\
\text { treatment }\end{array}$ & Elective surgical gastrostomy \\
\hline $\begin{array}{l}\text { Okutani et al. } \\
(2008)^{16}\end{array}$ & $27 / \mathrm{M}$ & Diarrhea & Cerebral palsy & A few mo & $\begin{array}{l}\text { Surgical } \\
\text { treatment }\end{array}$ & $\begin{array}{l}\text { Surgical gastrostomy and fistula } \\
\text { excision }\end{array}$ \\
\hline
\end{tabular}

PEG, percutaneous endoscopic gastrostomy.

fistula can be performed in patients with a large fistula opening that cannot be spontaneously closed. Even if the fistulous opening is small, endoscopic management would accelerate the blockage of fistula, leading to earlier oral feeding.

The majority of previous endoscopic interventions were conducted via colonoscopy by clipping the colonic side of the 
fistula opening. However, we performed endoscopic closure on the gastric side opening, because leakage of gastric juice through the fistula can disturb the spontaneous closure of the fistula. The method of endoscopic treatment is likely determined according to the size of the fistula opening. Small fistula tracts were treated only with hemoclips, but detachable snare with clips, over-the-scope clip, and cardiac septal defect closure device have been used for relatively large fistula openings. ${ }^{4,9,17-20}$ In our case, we used hemoclips to close the fistula, and argon plasma coagulation was performed before clipping to help mucosal adhesion. From our experience, and as observed in previously reported cases, whether endoscopic treatment entails closure of the gastric or colonic side depends on the case. Herein, we report a case in which the patient was treated by clipping the gastric side of the fistulous opening alone, while the patients in the majority of previous cases were treated by clipping the colonic side of the fistulous opening with or without the gastric side opening.

In conclusion, PEG-associated complications are expected to increase along with the increasing requirement for PEG. Clinicians should be aware of the typical symptoms of gastrocolocutaneous fistula in order to establish an early diagnosis and to provide proper treatment for the complications. Endoscopic closure can be an effective method for the treatment of a gastrocolocutaneous fistula.

\section{Conflicts of Interest}

The authors have no financial conflicts of interest.

\section{REFERENCES}

1. Hucl T, Spicak J. Complications of percutaneous endoscopic gastrostomy. Best Pract Res Clin Gastroenterol 2016;30:769-781.

2. Blomberg J, Lagergren J, Martin L, Mattsson F, Lagergren P. Complications after percutaneous endoscopic gastrostomy in a prospective study. Scand J Gastroenterol 2012;47:737-742.

3. Pitsinis V, Roberts P. Gastrocolic fistula as a complication of percutaneous endoscopic gastrostomy. Eur J Clin Nutr 2003;57:876-878.

4. Kim HS, Bang CS, Kim YS, et al. Two cases of gastrocolocutaneous fistula with a long asymptomatic period after percutaneous endoscopic gastrostomy. Intest Res 2014;12:251-255.

5. Smyth GP, McGreal GT, McDermott EW. Delayed presentation of a gastric colocutaneous fistula after percutaneous endoscopic gastrostomy. Nutrition 2003;19:905-906.

6. Croaker GDH, Najmaldin AS. Laparoscopically assisted percutaneous endoscopic gastrostomy. Pediatr Surg Int 1997;12:130-131.

7. Friedmann R, Feldman H, Sonnenblick M. Misplacement of percutaneously inserted gastrostomy tube into the colon: report of 6 cases and review of the literature. JPEN J Parenter Enteral Nutr 2007;31:469-476.

8. Tominaga K, Saigusa Y, Ito S, Hirahata K, Nemoto Y, Maetani I. Percutaneous endoscopic gastrostomy with the aid of a colonoscope to avoid gastrocolic fistula formation. Endoscopy 2007;39(Suppl 1):E112-E113.

9. Lee HJ, Choung RS, Park MS, et al. Two cases of uncommon complication during percutaneous endoscopic gastrostomy tube replacement and treatment. Korean J Gastroenterol 2014;63:120-124.

10. Yamazaki T, Sakai Y, Hatakeyama K, Hoshiyama Y. Colocutaneous fistula after percutaneous endoscopic gastrostomy in a remnant stomach. Surg Endosc 1999;13:280-282.

11. Stefan MM, Holcomb GW 3rd, Ross AJ 3rd. Cologastric fistula as a complication of percutaneous endoscopic gastrostomy. JPEN J Parenter Enteral Nutr 1989;13:554-556

12. Minocha A, Rupp TH, Jaggers TL, Rahal PS. Silent colo-gastrocutaneous fistula as a complication of percutaneous endoscopic gastrostomy. Am J Gastroenterol 1994;89:2243-2244.

13. Strodel WE, Lemmer J, Eckhauser F, Botham M, Dent T. Early experience with endoscopic percutaneous gastrostomy. Arch Surg 1983;118:449-453

14. Liu SY, Ng SS, Yip HC, Teoh AY, Chiu PW, Ng EK. Migration of a percutaneous endoscopic gastrostomy tube into the transverse colon: a forgotten cause of refractory diarrhea. Endoscopy 2010;42(Suppl 2):E324-E325.

15. Huang SY, Levine MS, Raper SE. Gastrocolic fistula with migration of feeding tube into transverse colon as a complication of percutaneous endoscopic gastrostomy. AJR Am J Roentgenol 2005;184(3 Suppl):S65-S66.

16. Okutani D, Kotani K, Makihara S. A case of gastrocolocutaneous fistula as a complication of percutaneous endoscopic gastrostomy. Acta Med Okayama 2008;62:135-138.

17. Hwang JH, Kim HW, Kang DH, et al. A case of endoscopic treatment for gastrocolocutaneous fistula as a complication of percutaneous endoscopic gastrostomy. Clin Endosc 2012;45:95-98.

18. Kim HS, Lee DK, Baik SK, Kwon SO. Endoscopic management of colocutaneous fistula after percutaneous endoscopic gastrostomy. Endoscopy 2002;34:430.

19. Melmed GY, Kar S, Geft I, Lo SK. A new method for endoscopic closure of gastrocolonic fistula: novel application of a cardiac septal defect closure device (with video). Gastrointest Endosc 2009;70:542-545.

20. Bertolini R, Meyenberger C, Sulz MC. First report of colonoscopic closure of a gastrocolocutaneous PEG migration with over-the-scopeclipsystem. World J Gastroenterol 2014;20:11439-11442. 